\title{
UNIVERSITYOF
}

FORWARD

THINKING

WESTMINSTER用

WestminsterResearch

http://www.westminster.ac.uk/westminsterresearch

\section{A Hybrid Paradigm for Modeling, Simulation and Analysis of Brand Virality in Social Media}

Li Shuliang, Li, Jim Z. and Geng, L.

This is a copy of the author's accepted version of a paper subsequently to be published in the proceedings of the 2015 Sixth International Conference on Intelligent Systems Design and Engineering Applications (ISDEA2015) Guiyang, China, 18-19 Aug 2015, IEEE .

It will be available online at:

http://ieeexplore.ieee.org/servlet/opac?punumber=1800333

(C) 2015 IEEE . Personal use of this material is permitted. Permission from IEEE must be obtained for all other uses, in any current or future media, including reprinting/republishing this material for advertising or promotional purposes, creating new collective works, for resale or redistribution to servers or lists, or reuse of any copyrighted component of this work in other works.

The WestminsterResearch online digital archive at the University of Westminster aims to make the research output of the University available to a wider audience. Copyright and Moral Rights remain with the authors and/or copyright owners.

Whilst further distribution of specific materials from within this archive is forbidden, you may freely distribute the URL of WestminsterResearch: ((http://westminsterresearch.wmin.ac.uk/)).

In case of abuse or copyright appearing without permission e-mail repository@westminster.ac.uk 


\title{
A Hybrid Paradigm for Modeling, Simulation and Analysis of Brand Virality in Social Media
}

\author{
Shuliang Li ${ }^{1,2}$, Jim Zheng Li ${ }^{3}$, Simon S. L. Li ${ }^{2}$, Lihui Geng ${ }^{2}$ \\ ${ }^{1}$ Westminster Business School, University of Westminster, London, NW1 5LS, UK \\ lish@westminster.ac.uk \\ ${ }^{2}$ School of Economics \& Management, Southwest Jiaotong University, Chengdu, Sichuan, 610031, China \\ simonxnjd@gmail.com; glihui@home.swjtu.edu.cn \\ 3 Typesoftly Solutions Limited, London, England, UK \\ jimzhengli@gmail.com
}

\begin{abstract}
Enhancing brand awareness through online social networks is increasingly pivotal to business success. This paper is concerned with a hybrid paradigm for modeling, simulation and analysis of brand virality in social media. In particular, mathematical models and graphical animation are proposed and formulated to represent the spread and viral process of a brand over social Web and mobile networks. Simulation prototype are also created to illustrate relevant ideas and concepts. Furthermore, a fuzzy logic-based framework is developed to evaluate the effectiveness and efficiency of brand virality. Our work provides a solid foundation for further investigation in this field.
\end{abstract}

Keywords - Brand virality; social media; modeling; simulation; intelligent software agent; fuzzy logic

\section{INTRODUCTION}

The creator and inventor of the World Wide Web, Sir Tim Berners-Lee said: "The web is a network of people". People communicate and share information with each other in the social Web environment.

According to $\mathrm{Li} \& \mathrm{Li}$ [5]: "Social media and associated tools, such as Facebook, are Web-based applications built upon Web 2.0 technologies. They enable and allow online interactions and communication amongst individuals and virtual communities for creating, co-creating, sharing, discussing, and amending user-produced contents [1, 2, 3]".

In this digital age, brand awareness can be increased by taking advantage of people's communication and information sharing over the Internet and social media platforms. Electronic Word-of-Mouth, and viral marketing in a broader perspective, is concerned with publishing and issuing brand information on the World Wide Web and online social media, and stimulate and encourage the audience to share and circulate the content.

Mills [4] proposed a conceptual framework for virality in social media, consisting of four elements: spreadability, propagativity, integration and nexus. Long and $\mathrm{Li}$ [7] reported some preliminary mathematical work, together with complex adaptive system modeling effort on evolutionary branding of products in dynamically changing markets. Abhishek et al. [11] proposed a model for quantifying the viral nature of an information item in an online social network.

In our study, taking into account of the complexity and the multi-facets of brand virality modeling and analysis, we propose a hybrid approach [6, 8, 9] that integrates the strengths of diverse methods and techniques for problemsolving.

\section{THE HYBRID PARADIGM}

The properties of branded content over social media may include such facets as dynamic spreading, viral nature with uncertainties, growth and decay of user engagement, brand building, brand damaging risks and associated effectiveness and efficiency of brand virality. Our hybrid paradigm matching the powers of different methods and techniques with the facets of online brand virality is given in Table 1.

Table 1. Hybrid paradigm for modeling, simulation and analysis of brand viarlity over social media

\begin{tabular}{|l|l|}
\hline $\begin{array}{l}\text { Properties of brand virality } \\
\text { and viral marketing }\end{array}$ & $\begin{array}{l}\text { Proposed modeling, simulation, decision } \\
\text { support and artificial intelligence } \\
\text { methods, techniques \& technologies }\end{array}$ \\
\hline $\begin{array}{l}\text { Brands related user traffic } \\
\text { flow, trends, mentions, buzz, } \\
\text { comments, likes, dislikes, } \\
\text { chats, consumer loyalty, etc. }\end{array}$ & $\begin{array}{l}\text { Social media \& Web analytics tools such as } \\
\text { Facebook Insights, Omniture, Google } \\
\text { Display Planner; expert system; intelligent } \\
\text { software agents }\end{array}$ \\
\hline $\begin{array}{l}\text { Dynamic spread, viral nature } \\
\text { with uncertainties, growth and } \\
\text { decay on the number of } \\
\text { engaged users; brand } \\
\text { building, and brand damaging } \\
\text { risks }\end{array}$ & $\begin{array}{l}\text { Mathematical and statistical methods; } \\
\text { intelligent software agents; complex } \\
\text { dynamics }\end{array}$ \\
\hline $\begin{array}{l}\text { Effectiveness and efficiency } \\
\text { of brand virality over social } \\
\text { media }\end{array}$ & Fuzzy logic; decision support techniques \\
\hline $\begin{array}{l}\text { Viral marketing and } \\
\text { advertising campaigns and } \\
\text { associated decision-making }\end{array}$ & $\begin{array}{l}\text { Fupteory; system } \\
\text { sumport; analytic hierarchy process (AHP); } \\
\text { human judgement, intuition and creativity }\end{array}$ \\
\hline
\end{tabular}


Li, Shuliang and Li, JZ and and Geng, LH (2015) A Hybrid Paradigm for Modeling, Simulation and Analysis of Brand Virality in Social Media. Proceedings of the Sixth International Conference on Intelligent Systems Design and Engineering Applications (ISDEA2015), Guiyang, China 18 Aug 2015. pp.26-29. IEEE-CPS. ISBN 978-1-4673-9393-5/15. DOI 10.1109/ISDEA.2015.16

The following sections will only focus on modeling, simulation and evaluation of brand virality in social media environments.

\section{THE MATHEMATICAL MODEL FOR ENGAGEMENT}

In the social media contexts, "reach" is the number of people who have seen the branded post.

There are also people who like the branded content, click it, share it, re-post it, provide comments and talk about this. Facebook defines engagement as including all clicks. Good understanding and analysis of user engagement to a brand will help improve customer relationships and brand loyalty.

With more audience engaged with a branded post, relevant brand image can be amplified.

With a serious of online posts, the estimated number of engaged users via a social media platform, say, Facebook.com, may be formulated as a simple exponential function [18]. When brand damaging and a decay situation occurs, the growth rate takes a negative value.

When tackling a real-world simulation problem, an exponential function may not work well due to uncertainties, ambiguities, and uncontrollable audience behavior. To be more realistic, we recommend to use a random number generation method and probability distributions, for example, the continuous uniform distribution, combined with dynamic displays and animation movies, to describe the changes, "growth" of engaged users, and count relevant numbers, and the online viral process.

A simplified illustration example of random user engagement simulation for a branded content is shown in Figure 1. Persons in green color are engaged across the social networks, while the white ones are the disengaged and the yellow icons are the reached. Netlogo software tool and multiple software agents, called Turtles, are coded and created to produce the illustration and simulation with graphical animation.

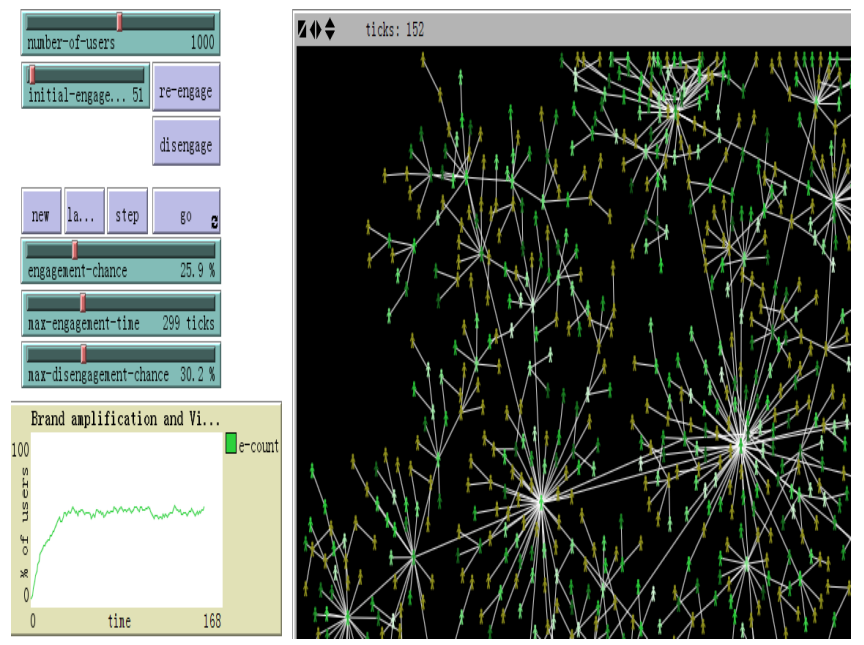

Figure 1. The screenshot for simulation of user engagement with dynamically displayed animation

\section{MATHEMATICAL MODEL FOR BRAND VIRALITY}

It is of crucial importance for us to understand, model and compute, and simulate brand virality in social Web contexts.

On the basis of Abhishek et al. [11]'s work and the Simple Pathogenic Epidemic Model, we now provide a model for brand virality in social media contexts and propose the following equation.

$$
B V=\ln \left(\left(R / R_{0} * r / R * E U\right) / t\right)
$$

where $B V$ - an index for brand virality; $R$ - cumulative reach of audience in a social network; $R_{0}$ - initial reach; $r$ - the daily reach number of people over social media; $t$ - the number of days; $E U$ - the sum of the number of engaged users who clicked, liked, shared, re-posted and commented on the brand item or content; In - natural logarithm.

A Netlogo simulation example of brand virality index on the basis of equation (1) is illustrated in Figure 2.

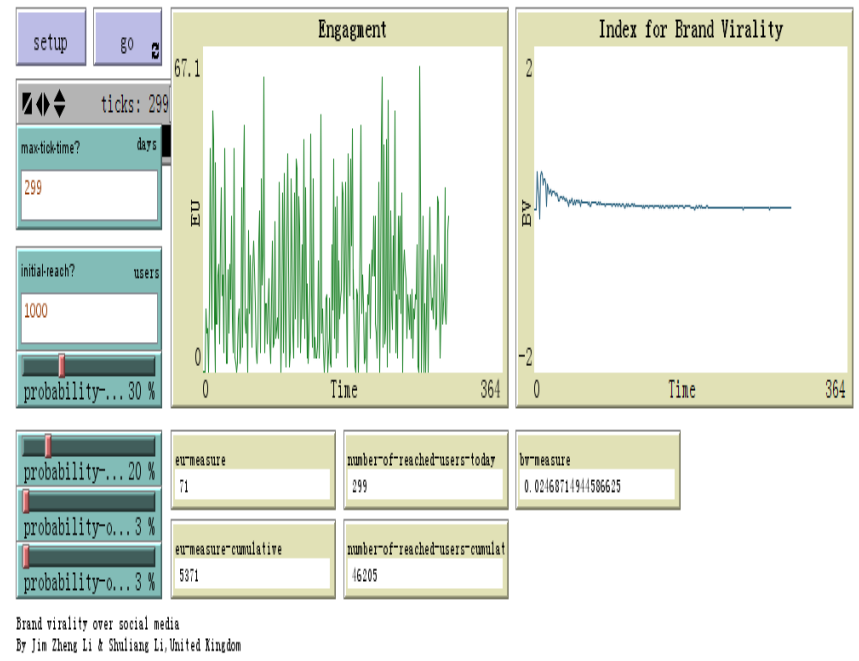

Figure 2. The screenshot for simulation of the brand virality

V. THE USE OF FUZZY LOGIC IN ASSESSING THE EFFECTIVENESS AND EFFICIENCY OF BRAND VIRALITY

A. Fuzzy logic and the space of the variables affecting brand virality in social media

'A fuzzy set is a class of objects with a continuum of grades of membership' [12, page 338]. Let $U$ be a universe of discourse, a collection of objects $\{u\}$. A fuzzy set $A$ in $U$ is characterized by a membership or compatibility function $\mu_{A}$ taking values in the interval $[0,1] . A$ in $U$ is represented as $[13,15]$ :

$A=\left\{\left(u, \mu_{A}(u)\right) \mid u \in U\right\}$

Based upon Fung et al [16]'s work, the set of variables (with values ranging from 1 to 10 , for example) that determine the effectiveness and 
Li, Shuliang and Li, JZ and and Geng, LH (2015) A Hybrid Paradigm for Modeling, Simulation and Analysis of Brand Virality in Social Media. Proceedings of the Sixth International Conference on Intelligent Systems Design and Engineering Applications (ISDEA2015), Guiyang, China 18 Aug 2015. pp.26-29. IEEE-CPS. ISBN 978-1-4673-9393-5/15. DOI 10.1109/ISDEA.2015.16

efficiency of brand virality can be expressed as a vector $H$ :

$H=\left(H_{1}, H_{2}, \ldots, H_{m}\right)$ in the fuzzy space of $U$

For instance, any value of the index for brand virality can be easily transformed into a scale of 1 to 10 .

For the input fuzzy vector $H$, there exists a real vector $w$ that represents the weights or relative importance for each of the variables, such that $w=\left(w_{1}, w_{2}, \ldots, w_{m}\right)$ which can be determined using the analytic hierarchy process (AHP).

We then aggregate the values of $H$ and $w$ to work out the value of an object, $u$, using the following formula:

$u=H_{1} \cdot w_{1}+H_{2} \cdot w_{2}+\ldots+H_{m} \cdot w_{m}$

\section{B. Fuzzification of the variables determining the effectiveness and efficiency of brand virality in social media}

Trapezoidal membership/compatibility functions are employed to fuzzify the aggregated scores for assessing brand virality over online social networks. For real numbers $a<=b<=c<=d$, the trapezoid $\Gamma(a, b, c, d)$ with amplitude one is defined as [17]:

$$
\begin{aligned}
& \Gamma(u)=0 \text { if } u<=a ; \\
& \Gamma(u)=(u-a) /(b-a) \text { if } a<u<=b ; \\
& \Gamma(u)=1 \text { if } b<u<=c ; \\
& \Gamma(u)=(d-u) /(d-c) \text { if } c<u<=d ; \\
& \Gamma(u)=0 \text { if } d<u ; \\
& \Gamma(u)=1 \text { if } a=b ; \\
& \Gamma(u)=1 \text { if } c=d .
\end{aligned}
$$

Here, $u \in U$ where $U$ is the universe of discourse or scale of the performance variable for brand virality.

\section{Fuzzy inference for assessing the effectiveness and efficiency of brand virality over social media}

On the basis of Zadeh [14]'s theory and principles for the management of uncertainty in fuzzy expert systems, the mechanism for evaluating the effectiveness and efficiency of brand virality is proposed below.

If we use $P$ to denote the name of the performance variable, and $\boldsymbol{T}(P)$ is the term set of $P$, that is, the collection of its linguistic values, then we have $\boldsymbol{T}(P)=$ (poor, good, excellent) with underlying fuzzy sets and certain degree of confidence or a grade of certainty. This is illustrated in Figure 3

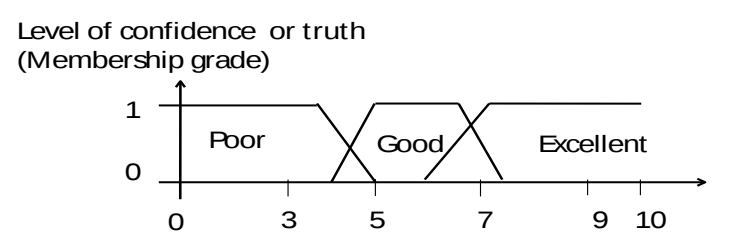

Aggregated score for the inputs to performance variables

Figure 3. Fuzzy membership functions for evaluating brand virality performance

Our system utilizes a strategy that begins with known facts and aims to infer and reach the conclusions implied by the facts or entries. The chaining control can be coded by applying the forward reasoning mechanism. The inputted data and personal judgement, pre-programmed "if - then" and fuzzy rules can be applied in a data-driven forward thinking way for assessing brand virality performance. The fuzzy rules for evaluating performance as "poor", "good" or "excellent" with certain degrees of truth are based upon the above-mentioned trapezoidal membership functions.

\section{HYPOTHESES FOR FURTHER RESEARCH}

On the basis of the literature $[5,8,9,10]$, the work discussed in the previous sections, and the authors' own reflection and synthesis of relevant research work, the following hypotheses are formulated for further investigation on this topic.

Hypothesis 1. Users of the hybrid paradigm for simulation and evaluation of brand virality over social media will achieve better understanding of the viral process than non-users.

Hypothesis 2. Users of the hybrid paradigm will obtain better insights about how a brand is viral and amplified across online social networks than non-users.

Hypothesis 3. Users of the hybrid paradigm will be able to acquire more knowledge about brand virality in social media contexts than non-users.

Hypothesis 4. Users of the hybrid paradigm will have more chance to reduce the risks for brand damaging in social media contexts than non- users.

Hypothesis 5. Users of the hybrid paradigm will obtain a better understanding of how consumer loyalty for a brand is affected by various factors in the social media contexts than non-users.

Hypothesis 6. Users of the hybrid paradigm will be able to simulate and explore more viral marketing or advertising alternatives for branding in social media contexts than nonusers

Hypothesis 7. Users of the hybrid paradigm will attain better coupling of simulation analysis with human judgment and intuition in the process of online branding than nonusers 
Li, Shuliang and Li, JZ and and Geng, LH (2015) A Hybrid Paradigm for Modeling, Simulation and Analysis of Brand Virality in Social Media. Proceedings of the Sixth International Conference on Intelligent Systems Design and Engineering Applications (ISDEA2015), Guiyang, China 18 Aug 2015. pp.26-29. IEEE-CPS. ISBN 978-1-4673-9393-5/15. DOI 10.1109/ISDEA.2015.16

Hypothesis 8 . Users of the hybrid paradigm will be able to make better improvements on their brand identity and image than non-users

Hypothesis 9. Users of the hybrid paradigm will be able to establish more customer loyalty for their brand than nonusers

\section{CONCLUSIONS}

This paper has been aimed to develop a hybrid framework for modeling, simulation and assessment of brand virality across online social networks. In our proposed paradigm, mathematical models and dynamic animation are employed to represent user engagement phenomenon with graphical animation, brand virality and spread. Examples have been provided to illustrate relevant concepts and ideas. Fuzzy logic has been applied to evaluate the effectiveness and efficiency of online brand building and virality.

Our work provides a good foundation for further research in this field.

In this digital age, managers want to build a brand, to achieve good brand building effects while avoiding any damage to their brand. We have sought to model and perform "what-if" analysis for the nature of the virality of branded contents across the online social networks. Our models can be used as a training tool. It can also be utilized to help managers in decision making for brand building, and viral and social media marketing.

Further work is being undertaken by the authors to extend the simulation prototype by coding more functions and incorporating more artificial intelligence components. Testing relevant hypotheses will also be a priority for the next stage of research.

\section{ACKNOWLEDGEMENTS}

The software tool used in relevant simulation examples is Netlogo.

This research project and the publication of this paper is financially supported by the University of Westminster staff research allowances (UK) and Sichuan 100-Talent Scheme grant (Grant decision document number: CHUAN ZU TONG [2012] 142) that is hosted by Southwest Jiaotong University, China.

\section{REFERENCES.}

[1] M. Kaplan. Users of the world, unite! The challenges and opportunities of social media. Business Horizons, 2010, 53(1): p. 61.

[2] H. K. Jan, K. Hermkens. Social media? Get serious! Understanding the functional building blocks of social media, Business Horizons, 2011, 54: 241-251.

[3] N. Booth, J. A. Matic, Mapping and leveraging influencers in social media to shape corporate brand perceptions. Corporate Communications: An International Journal, 2011, 16(3): 184 - 191.

[4] A. J. Mills. Virality in social media: the SPIN Framework. Journal of Public Affairs, 2012, 12(2): 162-169.

[5] S. Li, J. Z. Li, Jim. Web and social media dynamics, and evolutionary and adaptive branding: theories and a hybrid intelligent model. In: Advances in Neural Networks, Fuzzy Systems and Artificial Intelligence. WSEAS, 2014, pp.106-111.
[6] S. Li, J. Z. Li. Linking social media with open innovation: an intelligent model. In: Proceedings of the 7th international conference on intelligent computation technology and automation, 25th-26th October 2014, Changsha, China. IEEE-CPS , 2014, pp. 331-335.

[7] Q. Long, S. Li. Mathematical description and complex adaptive system modeling for evolutionary branding. In: Proceedings of the 7th international conference on intelligent computation technology and automation (ICICTA2014), 25th-26th October 2014, Changsha, China. IEEE-CPS, pp. 352-355.

[8] S. Li. The development of a hybrid intelligent system for developing marketing strategy. Decision Support Systems, 2000, 27(4): 395409.

[9] S. Li, J. Z. Li. AgentsInternational: Integration of multiple intelligent agents, simulation, knowledge bases and fuzzy logic for international marketing decision making. Expert Systems with Applications (an international journal), 2010, 37(3): 2580-2587.

[10] S. Li, J. Z. Li. WebInternational: combining web-based knowledge automation, fuzzy rules and online databases for international marketing planning. Expert Systems with Applications, 2010, 37 (10): 7094-7100.

[11] V. Abhishek, S. Akshay, M. Dharmaprakash, G. Rajiv, G. Utkarsh. Quantifying virality of information in online social networks. International Journal of Social Networking and Virtual Communities, 2012, 1(1): 19 30

[12] L. A. Zadeh. Fuzzy sets. Information and Control, 1965, 8(3): 338353.

[13] L. A. Zadeh. Fuzzy logic and approximate reasoning. Synthese, 1975, 30 (3/4): 407-428.

[14] L. A. Zadeh. The role of fuzzy logic in the management of uncertainty in expert systems. Fuzzy Sets and Systems, 1983, 11: 199-227.

[15] C. C. Lee. Fuzzy logic in control systems: fuzzy logic controller part I. IEEE Transactions on Systems, Man and Cybernetics,1990, 20(2): 404-418.

[16] R. Y. K. Fung, K. Popplewell, J. Xie. An intelligent hybrid system for customer requirements analysis and product attribute targets determination. International Journal of Production Research, 1998, 36(1): $13-34$.

[17] J. B Levy, E. Yoon. Modeling global market entry decision by fuzzy logic with an application to country risk assessment. European Journal of Operational Research, 1995, 82: 53-78.

[18] https://en.wikipedia.org/wiki/Exponential_growth (Accessed on 12th July 2015) 